\title{
INORGANIC NITROGEN REMOVAL IN TROPICALLY COASTAL AQUACULTURE PONDS USING INTEGRATED BIOREMEDIATION
}

\author{
Do Manh Hao*, Dao Thi Anh Tuyet, Hoang Thi Thanh Nga, \\ Nguyen Tien Dat, Le Xuan Sinh, Tran Dinh Lan \\ Institute of Marine Environment and Resources, VAST \\ "E-mail: haodm@imer.ac.vn
}

Received: 20-4-2017

\begin{abstract}
Bioremediation technology has been emergently considered as an economic and environmental-friendly manner to treat inorganic nitrogen in tropically coastal aquaculture ponds. Two laboratory scale experiments were conducted to examine efficacy of nitrogen removal of some bioremediators. The results indicated that total ammonia nitrogen (TAN) and nitrite concentrations of treatments with inoculation of the nitrifying bacterial cultures were significantly lower than those of the treatments without inoculation just after three days and one day of experiment, respectively. TAN in treatments with inoculation was removed at $76.0 \%$ while that without inoculation was just removed at $53.7 \%$. Nitrite in treatments without inoculation increased duration of first 20 experiment days while nitrite in treatments with inoculation decreased to $50 \%$ just after one day. For treatments with inoculation of denitrifying bacterial cultures, effect of nitrate removal was clear within one day after beginning of the experiment. The present of macroalgae Gracilaria sp. promoted TAN and nitrite removal after two to three days of the experiment. Moreover, the addition of $\mathrm{CaCO}_{3}$ could enhance TAN and nitrite removal in comparison to the control treatments.
\end{abstract}

Keywords: Coastal aquaculture, inorganic nitrogen, bioremediation, nitrifying bacteria, denitrifying bacteria.

\section{INTRODUCTION}

Reduced fishery harvests and increased consumer demand for seafood have precipitated an increase in intensive aquacultural farming, particularly in coastal shrimp culture. However, the rapid development of coastal aquaculture has led to adverse environmental impacts. Metabolic waste of culture organisms and decomposition of uneaten feed, particularly inorganic nitrogen compounds usually accumulate at concentrations much higher than environmental carrying capacity. The excess inorganic nitrogen became toxicity and reduced shrimp growth rate and suppressed immune competence [1-4]. One of the major environmental concerns in aquatic animal cultivation is the discharge of wastewaters directly into coastal waters. Wastewater pollutants promote organic enrichment, sedimentation and toxicity. This set of factors results in the deterioration of coastal ecosystems and consequent loss of biodiversity and primary productivity [5-10].

In order to solve the pollutant issues in coastal intensive aquaculture, several approaches have been developed in recent years for control of nitrogen compounds. Bioaugmentation well-known as the seeding of enriched nitrifying and denitrifying cultures into intensive aquaculture has been studied. Application of nitrifiers into shrimp ponds can lead to decrease in ammonia and nitrate 
nitrogen in shrimp ponds [11-16]. In contrast, other studies have indicated that effect of the probiotics containing non-indigenous nitrifying cultures is not stable as they will be edged out by the competing native microorganisms, besides facing growth inhibition and prolonged acclimation period $[17,18]$.

Biostimulation known as nutrient supplementation, oxygen aeration, surface substrata and so on is still limited but the primary results showed the prospects. Diab and Shilo [19] reported that Nitrosomonas sp. and Nitrobacter sp. attached to the particles of bentonite, $\mathrm{CaCO}_{3}$, amberlite had activity much stronger than free-living strains; the attached bacteria survived in anaerobic conditions for several weeks while free-living bacteria only survived for few days. Preceding studies also showed that activities of nitrifying bacteria improved significantly if attached to other substrata such as zeolite, good particle [20, 21]. In addition, Barik et al., [16] indicated that the application of enriched nitrifying bacteria together with oxygen aeration improved ammonia removal. Alkalinity in the form of carbonate and bicarbonate has been used as a nutrient element for nitrifying bacteria and additive for maintenance of $\mathrm{pH}$ buffering capacity in the nitrification in recirculating aquaculture systems. Chen et al., [22] recommended that a higher alkalinity concentration of $200 \mathrm{mg} . \mathrm{L}^{-1}$ was needed to maintain maximum nitrification rate in recirculating aquaculture systems.

The use of macro-algae as nutrient absorbers has proven to be a valid alternative for nutrient bioremediation. The most frequently tested organisms were Gracilaria sp. which absorbs dissolved inorganic nutrients [5, 23-25]. The present study examined in laboratory-scale the in-situ bioremediation potential of indigenous nitrifier and denitrifier cultures, substrata, macroalgae Gracilaria sp. and alkalinity on inorganic nitrogen removal in coastal intensive aquaculture ponds.

\section{MATERIAL AND METHODS}

\section{Enrichment of nitrifying bacterial cultures}

The nitrifying bacterial strains isolated from shrimp pond sediments along coastal zone of Hai Phong city, in the northeast of Vietnam, were enriched primarily in sterilized $250 \mathrm{~mL}$ conical flasks containing a working volume of $100 \mathrm{~mL}$ of mineral culture media (according to Watson et al., [26]) at $28^{\circ} \mathrm{C}$ on a rotary shaker, and substrate concentrations were $20 \mathrm{mg} . \mathrm{L}^{-1}$ for Nitrosomonas sp. and $10 \mathrm{mg} \cdot \mathrm{L}^{-1}$ for Nitrobacter sp. All of the flasks were monitored daily for substrate concentrations and $\mathrm{pH}$ adjustment. Sub-culture into secondary media at a 1:9 ratio $(\mathrm{v} / \mathrm{v})$ was carried out when the growth of cultures entered near stationary phase, marked with the cessation of substrate consumption. Sub-culturing is terminated when time for substrate removal was considerably shortened down to $30-40 \mathrm{~h}$.

To prepare immobilized nitrifying bacterial cultures (INBC), the inoculums of secondary enriched nitrifying bacterial culture (NBC) were incubated into $500 \mathrm{~mL}$ conical flasks with an initial TAN and nitrite concentration of $20 \mathrm{mg} . \mathrm{L}^{-1}$ and $10 \mathrm{mg} . \mathrm{L}^{-1}$, respectively. The flasks were kept in darkness and continuously aerated; $\mathrm{pH}$ was maintained between 7.5 and 8.0. When the log phase of TAN and nitrite removal was detected, sterile zeolite particles (autoclaved at $121^{\circ} \mathrm{C}, 15 \mathrm{~min}$ ) were added into cultures. Culture immobilization onto zeolite particles was then undertaken at $10 \mathrm{~h}, 30 \mathrm{~h}$ and $60 \mathrm{~h}$ to determine the optimal immobilization period [20].

\section{Enrichment of denitrifying bacterial cultures (DBC)}

The isolated denitrifying bacterial strains were enriched primarily in $100 \mathrm{~mL}$ sterile conical flasks containing a working volume of $50 \mathrm{~mL}$ glucose-yeast extract media with $\mathrm{N}$ $\mathrm{NO}_{3}^{-} 0.1$ g.L $\mathrm{L}^{-1}$ at $28^{\circ} \mathrm{C}$ without shaking. All flasks were monitored every 10 hours for substrate concentrations. Sub-culture into secondary media at a 1:9 ratio $(\mathrm{v} / \mathrm{v})$ was carried out when the growth of cultures entered near stationary phase, marked with the cessation of substrate consumption. Sub-culturing was terminated when time for substrate removal was considerably shortened down to $8-12 \mathrm{~h}$. 
Acclimatization of macroalgae Gracilaria sp.

Specimens of Gracilaria sp. were collected at Lach Tray estuary $\left(20^{\circ} 45^{\prime} 27^{\prime \prime} \mathrm{N}\right.$; $\left.106^{\circ} 46^{\prime} 32^{\prime \prime} \mathrm{E}\right)$ located in the northeast of Vietnam. After collection, the specimens were taken to the laboratory where they were washed with seawater to remove sediment. Then the macroalgae were kept in an aquarium containing $50 \mathrm{~L}$ of seawater that was collected from aquaculture canal of Lach Tray estuary, under constant aeration and photoperiod of 12:12 h light:dark cycle. The conditions were maintained for 10 days of pre-acclimatization until starting of the experiment.

\section{Experimental design}

\section{Experimental design 1}

The experiment was set up to focus on effect evaluation of the additive of enriched nitrifying bacterial cultures and different substrata on the removal of TAN and nitrite. The experiment was designed into ten treatments in duplicates as follows:

I1S: with inoculum of NBC at $100 \mu \mathrm{L} . \mathrm{L}^{-1}$, without substratum;

I2S: without inoculum of NBC, without substratum;

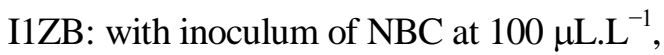
with zeolite substratum;

I2ZB: without inoculum of NBC, with zeolite substratum;

I1SB: with inoculum of NBC at $100 \mu \mathrm{L} . \mathrm{L}^{-1}$, with sand substratum;

I2SB: without inoculum of NBC, with sand substratum;

I1GB: with inoculum of $\mathrm{NBC}$ at $100 \mu \mathrm{L} . \mathrm{L}^{-1}$, with gravel substratum;

I2GB: without inoculum of NBC, with gravel substratum;

I1CB: with inoculum of NBC at $100 \mu \mathrm{L} . \mathrm{L}^{-1}$, with coral fragment substratum;

I2CB: without inoculum of NBC, with coral fragment substratum.
Experiment was carried out in twenty aquaria $(25 \times 25 \times 30 \mathrm{~cm})$ that were stocked with four of Asian tiger shrimp (Penaeus monodon), post 15 . Because the seawater in aquaculture canal was received directly from the discharge of many aquaculture ponds, we chose the water sources to carry out experiment. Each aquarium was filled up to $15 \mathrm{~L}$ with the seawater collected from aquaculture canal in Lach Tray estuary. Twenty aerators were used in aquaria for aeration. Aeration in aquaria tanks was achieved by passing of the air from air pump through a submerged block of porous material called air stone along with regulators. Shrimp was fed 5 times a day for 37 days, $24 \mathrm{mg}$ food per each time for each aquarium. Temperature, $\mathrm{pH}, \mathrm{DO}$ and dissolved nutrients (TAN, nitrite and nitrate) were monitored daily.

\section{Experiment design 2}

The experiment was set up to clarify further the effect of individual bioremediators as well as the comprehensive effect of those bioremediators on inorganic nitrogen removal. The experiment was designed into six treatments in triplicate as follows:

Control: without any additives.

INBC-DBC: with inoculums of INBC and DBC at $100 \mu \mathrm{L} . \mathrm{L}^{-1}$.

Zeolite: with TAN saturated zeolite.

Gracilaria: with Gracilaria sp.

$\mathrm{CaCO}_{3}$ : with $\mathrm{CaCO}_{3}$.

INBC-DBC-Zeolite- $\mathrm{CaCO}_{3}$ : with inoculums of INBC and DBC, and addition of zeolite and $\mathrm{CaCO}_{3}$.

Experiment was carried out in eighteen aquaria $(45 \times 45 \times 40 \mathrm{~cm})$ that were stocked with twelve of Asian tiger shrimp (Penaeus monodon), post 15 each aquarium. The aquarium was added a layer of $5 \mathrm{~cm}$ of sand bed and filled with seawater up to $50 \mathrm{~L}$. The sand and seawater were collected from aquaculture canal in Lach Tray estuary. Twelve aerators were used in aquaria for aeration. Aeration in aquaria tanks was achieved by passing of the air from air pump through a 
submerged block of porous material called air stone along with regulators. Shrimp were fed 4 times a day for 11 days, $0.4 \mathrm{~g}$ food per each time. Temperature, $\mathrm{pH}, \mathrm{DO}$ and dissolved nutrients (TAN, nitrite and nitrate) were monitored daily.

\section{Analytical procedures}

Dissolved oxygen, water temperature and salinity were measured by using YSI model 57 dissolved oxygen meter (YSI Incorporated, Ohio, USA) and Atago refractometer (Atago Co., LTD, Tokyo, Japan), respectively. $\mathrm{pH}$ was measured with the help of a $\mathrm{pH}$ meter (704, Metrohm, Germany). TAN was analyzed by phenate method described by Solórzano [27]. Nitrite-nitrogen $\left(\mathrm{N}-\mathrm{NO}_{2}{ }^{-}\right)$was measured by diazotization method described by Strickland and Parson [28]. Nitrate nitrogen $\left(\mathrm{N}-\mathrm{NO}_{3}{ }^{-}\right)$was firstly reduced into $\mathrm{NO}_{2}^{-}$by cadmium column, and then formed nitrite measured by diazotization method [28].

\section{Statistical analysis}

Significant differences of variables (TAN, $\mathrm{N}-\mathrm{NO}_{2}^{-}, \quad \mathrm{N}-\mathrm{NO}_{3}{ }^{-}$) between treatments with inoculation of NBC and treatments without inoculation of NBC in the first experiment were analyzed by $\mathrm{t}$-Test. Those of the variables among six treatments in second experiment were analyzed by simple analysis of variance (ANOVA). The statistical analysis was performed using Excel package 2010 (Microsoft).

\section{RESULTS AND DISCUSSION}

\section{Effect of enriched nitrifying bacteria cultures on TAN removal}

In the first experiment, TAN concentration of all treatments tended to decrease during experimental time course. TAN concentration of the treatments with inoculation of nitrifying bacteria cultures (NBC) was lower than that of the treatments without inoculation of NBC. Just after three days of the experiment, average TAN concentration of the treatments with inoculation of NBC was significantly lower than that of the treatments without inoculation of NBC $(p<0.005)$ (fig. 1a). TAN concentrations in treatments with inoculation of
NBC decreased $76.0 \%$ while those without inoculation just decreased $53.7 \%$ in comparison with the first experiment day. After five days of the experiment, TAN concentration of the treatments with inoculum was about 0.016 mg. $\mathrm{L}^{-1}$ TAN removal at $99.4 \%$ while TAN concentration of the treatments without inoculum was about $0.835 \mathrm{mg} . \mathrm{L}^{-1}$ TAN removal at $67.8 \%$.

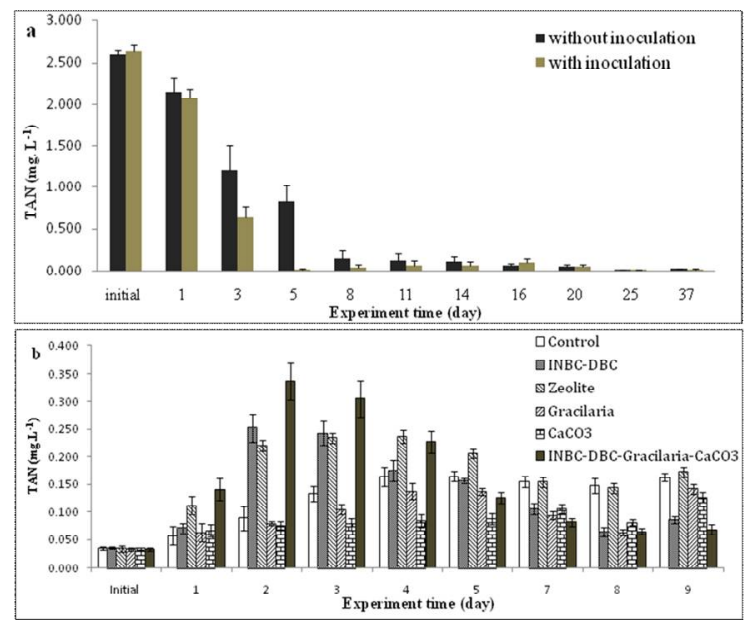

Fig. 1. Temporal variation of TAN concentration of different treatments,

(a): Treatments with inoculation and without inoculation in the first experiment,

(b): Treatments with inoculation of INBC-DBC and treatments with the addition of different

bioremediators in the second experiment

In the second experiment, TAN concentration of the treatments with inoculation of INBC-DBC, zeolite particles, and INBCDBC-Zeolite- $\mathrm{CaCO}_{3}$ all tended to be higher than that of the control treatment during first four days of the experiment. Then, TAN concentration of the treatment with inoculation of INBC-DBC and INBC-DBC-Zeolite- $\mathrm{CaCO}_{3}$ tended to be lower than that of the control treatment while TAN concentration in treatment with zeolite particles was higher than TAN concentration in control treatment (fig. 1b). The result showed that in the first four days of the experiment, TAN of the treatments with inoculation of INBC-DBC, zeolite particle and INBC-DBC-Zeolite-CaCO${ }_{3}$ were produced by ammonification of $\mathrm{DBC}$ and TAN release of 
ammonium-saturated zeolite particles. TAN of the treatment with INBC-DBC lower than TAN of the control treatment from $5^{\text {th }}-9^{\text {th }}$ day proved that the inoculation of INBC distributed the removal of TAN of the treatments with INBC-DBC and INBC-DBC-Zeolite-CaCO ${ }_{3}$. TAN of the treatment with INBC-DBC-Zeolite$\mathrm{CaCO}_{3}$ much lower than TAN of the treatment with INBC-DBC showed synergy effect of immobilized nitrifying bacteria and addition of $\mathrm{CaCO}_{3}$ in TAN removal.

The enriched inoculums of indigenous nitrifying bacteria in both suspended and attached states had significant effect on TAN removal within five days of the experiment. Study results of Grommen et al., [29] and Barik et al., [16] had shown that ammonia nitrogen concentration in treatments with Nitrosomonas and Nitrobacter inoculums decreased from 10 $\mathrm{mg} \mathrm{L}^{-1}$ to below the minimum limit (0.3 mg. $\left.\mathrm{L}^{-1}\right)$ within 3-5 days after inoculation.

\section{Effect of enriched nitrifying bacterial cultures on nitrite removal}

Just after one day of the first experiment, average $\mathrm{NO}_{2}^{-}$concentration of the treatments with inoculation of NBC was significantly lower than that of the treatments without inoculation of NBC $(p<0.001)$. Nitrite concentration in treatments with inoculation decreased $50 \%$ compared to that on the first day while nitrite concentration in treatments without inoculation increased twice. During sixteen days of the experiment, $\mathrm{NO}_{2}{ }^{-}$ concentration of the treatments with inoculation of NBC tended to decrease from $0.06 \mathrm{mg} . \mathrm{L}^{-1}$ on the first day to $0.03 \mathrm{mg} . \mathrm{L}^{-1}$ on the sixteenth day while $\mathrm{NO}_{2}{ }^{-}$concentration of the treatments without of NBC tended to increase from 0.06 mg. $\mathrm{L}^{-1}$ on the initial day to $0.13 \mathrm{mg} . \mathrm{L}^{-1}$ on the sixteenth experimental day. Since twenty days of the experiment, there were significant differences $(p<0.05)$ in $\mathrm{NO}_{2}^{-}$concentrations between treatments with and without inoculation of NBC at the same time (fig. 2a). The result showed that NBC could improve considerably nitrite removal only after one day and the effect of nitrite removal could last for sixteen days.
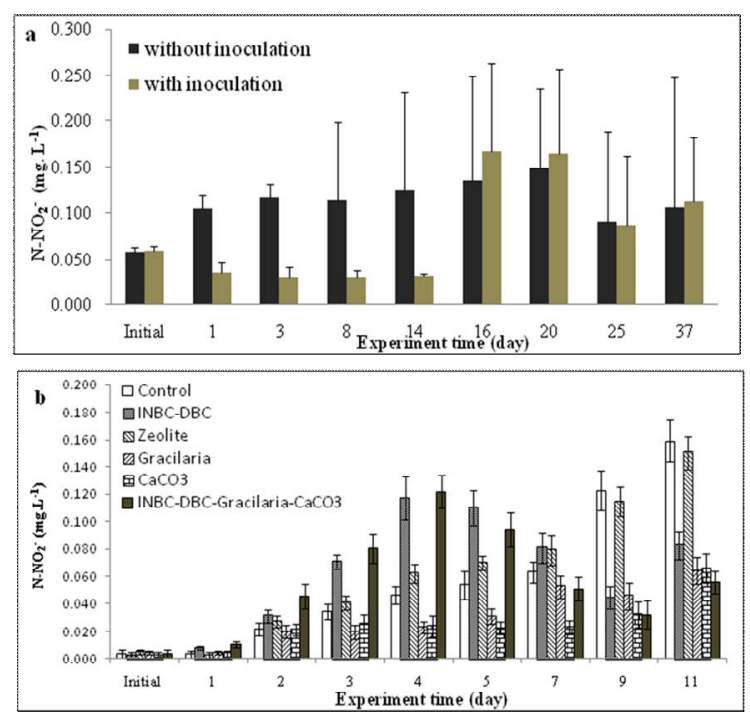

Fig. 2. Temporal variation of nitrite concentration of different treatments,

(a): Treatments with inoculation and without inoculation in the first experiment,

(b): Treatments with inoculation of INBC-DBC and treatments with the addition of different

bioremediators in the second experiment

Just after one day of the second experiment, $\mathrm{NO}_{2}^{-}$concentration of the treatments with inoculation of INBC-DBC and INBC-DBCZeolite- $\mathrm{CaCO}_{3}$ was significantly higher than that of the control treatment $(p<0.05)$. After two days of the experiment, $\mathrm{NO}_{2}{ }^{-}$ concentration of the treatment with supplement of zeolite was significantly higher than that of the control treatment $(p<0.05)$ (fig. 2b). Being similar to the dynamic trend of TAN concentration, $\mathrm{NO}_{2}^{-}$concentration of the treatments with inoculation of INBC-DBC and INBC-DBC-Zeolite- $\mathrm{CaCO}_{3}$ was higher than that of the control treatment during first five days of the experiment and then that of the treatments was much lower than that of the control treatment. Meanwhile $\mathrm{NO}_{2}{ }^{-}$ concentration of the treatment with supplement of zeolite was not significantly lower than that of the control treatment since next days of the experiment. The result showed that INBC distributed considerably the removal of $\mathrm{NO}_{2}{ }^{-}$of the treatment with inoculation of INBC. However, during the first day of the experiment, high $\mathrm{NO}_{2}^{-}$concentration of the 
treatments was caused by ammonification of DBC, TAN and $\mathrm{NO}_{2}^{-}$release from zeolite particles.

\section{Effect of enriched denitrifying bacterial cultures on nitrate removal}

Effect of denitrifying bacterial cultures (DBC) on nitrate removal was proven in the second experiment, nitrate concentration of the treatments with inoculation of DBC including of INBC-DBC and INBC-DBC-Zeolite-CaCO decreased strongly from $1.10 \mathrm{mg} . \mathrm{L}^{-1}$ on initial day to $0.06 \mathrm{mg} . \mathrm{L}^{-1}$ on first day of the experiment. Then nitrate concentration of the treatments was always maintained at low level in comparison to the control treatment (fig. 3). The vast majority of aquaculture ponds accumulated nitrate but there were very few studies interested in the nitrate removal in coastal aquaculture. Recently, there were some studies interested in development of denitrification reactors integrated into recirculating aquaculture systems [30-32].

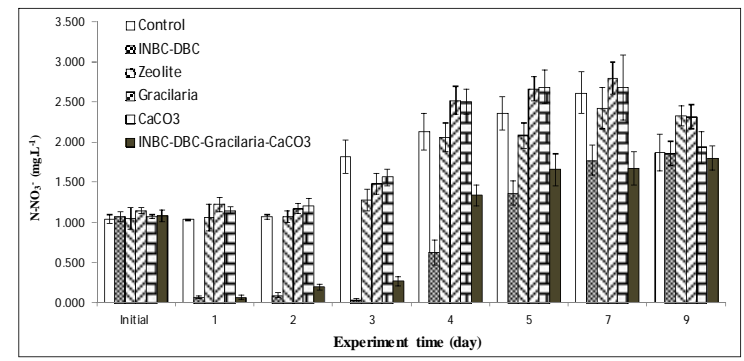

Fig. 3. Temporal variation of nitrate concentration in treatments with different bioremediators in second experiment

\section{Effect of substrata on TAN removal}

In the first experiment, we used four different substrata to assess their effect on removal of TAN and nitrite. For the treatments with inoculation of $\mathrm{NBC}$, there were no significant differences in TAN concentration among those treatments on first day of the experiment. Except the treatment with substratum of sand, TAN of the treatment was maintained at concentration significantly lower than that of the other treatments. From the third day of the experiment, average TAN concentration of the treatments with supplement of substrata tended to be lower than TAN of the treatment without supplement of substrata (fig. 4a). For the treatments without inoculation of NBC, average TAN concentrations between treatments with supplement of substrata and without supplement of substrata were not significantly different on the first day of experiment. From the third day of the experiment, average TAN concentrations of the treatments with supplement of substrata tended to be lower than those of the treatments without supplement of substrata (fig. 4b). The result showed that presence of substrata in environment could contribute to improving TAN removal in both conditions with and without inoculation of NBC.

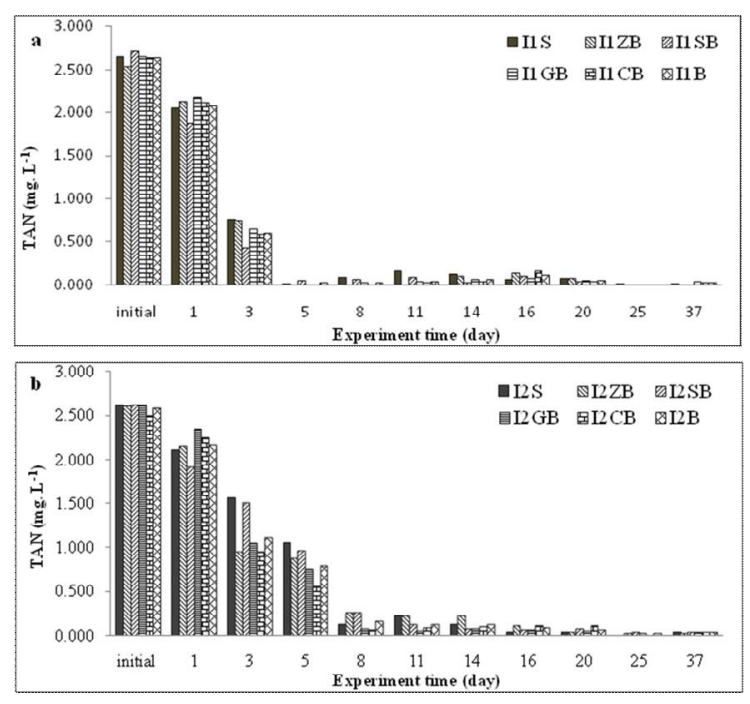

Fig. 4. Temporal variation of TAN in treatments with different substrata,

(a): With inoculation of NBC, (b): Without inoculation of NBC

For the treatments with inoculation of NBC, TAN concentration of the treatment supplied with substratum of sand was much lower than that of the other treatments on the first and third days of the experiment. From the fifth day of the experiment, because TAN in all treatments at different times was maintained at low concentration, less than $0.163 \mathrm{mg} . \mathrm{L}^{-1}$, we could not find considerable difference in TAN concentrations among treatments with different 
substrata. For the treatments without inoculation of $\mathrm{NBC}$, on the first day of the experiment, TAN concentration of the treatment with supplement of sand substratum was lower than that of the other treatments. But on the third day of the experiment, TAN concentration of the treatment was higher than that of the other treatments. On the fifth day of the experiment, TAN concentration in the treatment with supplement of coral was lowest, followed by that with supplement of gravel, zeolite and sand (fig. 4a, 4b). From the eighth day of experiment, we could not find a clear trend in TAN removal of the treatments with different substrata. The results showed that although different substrata had TAN removal effect at different levels, we could not find out considerable difference in TAN removal among those treatments with supplement of the four different substrata.

\section{Effect of substrata on nitrite removal}

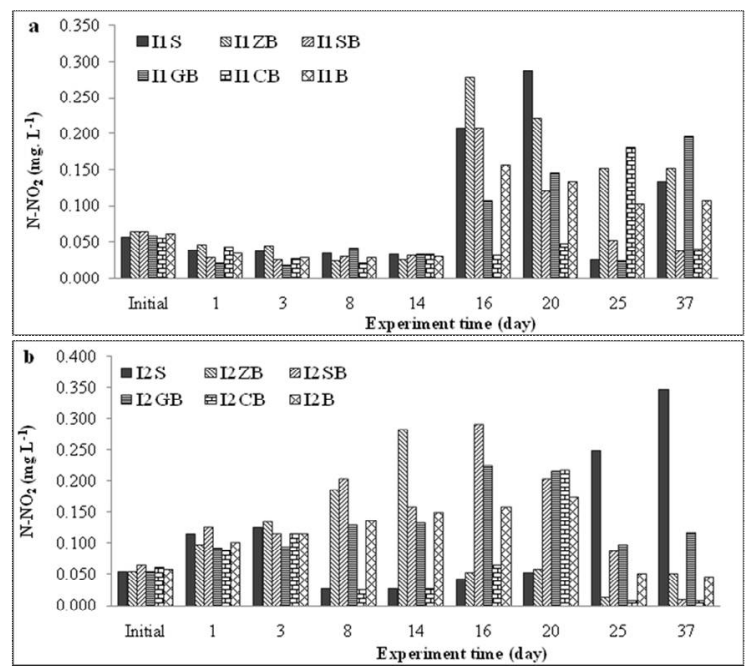

Fig. 5. Temporal variation of nitrite in treatments with different substrata,

(a): With inoculation of NBC; (b): Without inoculation of NBC

For the treatments with inoculation of NBC, average nitrite concentration in the treatments with supplement of substrata was lower than that in the treatments without supplement of substrata during time course of the experiment. However, for the treatments with inoculation of NBC, average nitrite concentrations in the treatments with supplement of substratum were lower than those in the treatments without substratum on the first and third days of the experiment. From the eighth to twenty fifth days of the experiment, average nitrite concentration of the treatments with substrata was much higher than nitrite in the treatments without substratum. From thirty seventh to forty fourth days, average nitrite concentration in the treatments with substrata was much lower than nitrite concentration in the treatments without substratum (fig. 5a). The result showed that effect of the application of substrata on nitrite removal was enhanced in synergy with inoculation of NBC.

Effect of nitrite removal of different substrata in treatments with inoculation of NBC is showed in fig. 5a. Although nitrite concentrations in treatments with different substrata were not similar at given time, we could not find a clear trend of distinction in nitrite concentration throughout time course of experiment. Except treatment with supplement of coral substratum, nitrite concentration in the treatment was lower than that in other treatments, particularly at the last time of the experiment. In treatments without inoculation of NBC, effect of nitrite removal of different substrata is showed in fig. 5b. Similar to treatments with supplement of substrata, there was not a general trend of distinction in nitrite concentration throughout time course of the experiment. However, nitrite concentration in the treatment with supplement of coral substratum was lower than that in the other treatments, particularly at the last time of the experiment.

TAN and nitrite in the treatments with supplement of substrata were maintained at concentrations lower significantly than those in the treatments without supplement of substrata. The trend was clearer in the treatments with inoculation of NBC. However, the study has not revealed removal effect of the inorganic nitrogen of four chosen different substrata.

\section{Effect of Gracilaria sp. on inorganic nitrogen removal}


Fig. 1b showed effect of Gracilaria sp. on TAN removal in the second experiment. TAN concentration of the treatment with application of the macroalgae Gracilaria was significantly lower than that of the control treatment after second day of the experiment $(p<0.05)$. Then TAN concentrations in the treatment with application of the macroalgae Gracilaria were lower than those in the control treatment throughout time course of the experiment.

Fig. 2b showed effect of Gracilaria sp. on nitrite removal in the second experiment. Nitrite concentration of the treatment with application of Gracilaria sp. was significantly lower than that of the control treatment after three days of the experiment $(p<0.05)$. Then, nitrite concentrations in the treatment with application of the macroalgae Gracilaria were much lower than those in the control treatment throughout time course of the experiment $(p<0.001)$.

Fig. 3 showed effect of Gracilaria sp. on nitrate removal in the second experiment. Nitrate concentrations in treatment with application of macro-algae Gracilaria tended to be higher than those in control treatment throughout time course of experiment. Just after one day of the experiment, nitrate concentration of the treatment with application of the macroalgae Gracilaria was significantly higher than nitrate of the control treatment $(p<0.05)$.

The present study showed that Gracilaria sp. could be used as a bioremediator in the treatment of TAN and nitrite in coastal aquaculture. According to study results of Marinho-Soriano et al. [24], macro-algae Gracilaria caudata performed well in absorbing nitrogen forms. According to McGowan [33], Ando et al. [34], sediment characteristics decided nitrification rate of indigenous bacteria, sand sediment with seagrass Zostera marina was demonstrated to effectively remove ammonia compared with the sediment without the seagrass.

\section{Effect of alkalinity on inorganic nitrogen removal}

Effect of alkalinity on TAN removal in the second experiment is showed in fig. 1b. TAN concentration of the treatment with application of $\mathrm{CaCO}_{3}$ was significantly lower than TAN concentration of the control treatment $(p<0.05)$. Then, nitrate concentrations of the treatment with application of $\mathrm{CaCO}_{3}$ were much lower than those in the control treatment throughout experimental time.

Effect of alkalinity on nitrite removal in the second experiment is showed in fig. $2 b$. Nitrite concentration of the treatment with application of $\mathrm{CaCO}_{3}$ was significantly lower than that of the control treatment after three days of the experiment $(p<0.05)$. Then nitrite concentrations in the treatment were much lower than those in the control treatment $(p<0.001)$.

Effect of alkalinity on nitrate removal in the second experiment is showed in fig. 3. Nitrate concentration in treatment with application of $\mathrm{CaCO}_{3}$ was lower significant than that in control treatment $(p<0.05)$ after just one day of experiment. Then nitrate concentrations of the treatment with application of $\mathrm{CaCO}_{3}$ were much higher than those in the control treatment $(p<0.001)$.

According to Chen et al. [35], the rate of nitrification would be reduced when alkalinity was below 40 g.m ${ }^{-3}$. For the case of nitrification, Gujer and Boller [36] reported that alkalinity level of at least $75 \mathrm{mg} . \mathrm{L}^{-1}$ was needed to maintain maximum nitrification rate in nitrifying biofilters of municipal wastewater treatment. In fact, alkalinity in the form of carbonate and bicarbonate was a nutrient element for nitrifying bacteria. In addition, alkalinity provided the buffering capacity that was necessary to prevent $\mathrm{pH}$ changes due to acid production nitrification process [22].

\section{CONCLUSIONS}

The study demonstrated that the indigenous nitrifying and denitrifying bacterial cultures, the macro-algae Gracilaria sp. and $\mathrm{CaCO}_{3}$ were potential bioremediators in treatment of TAN, nitrite and nitrate in tropically coastal intensive aquaculture. These technologies were feasible options in terms of economics and environmental concerns. In this study, we also demonstrated effect of substrata on TAN and 
nitrite removal, TAN and nitrite in the treatments with supplement of substrata were maintained at concentrations lower than those in the treatments without supplement of substrata. The trend was clearer for the treatments with inoculation of NBC.

Acknowledgments: The work was supported by the research grant from National Foundation for Science and Technology Development (Project code: 106-NN.05-2015.75), VAST.DA47.DA.12/15-18 and CCoreRENSEA (JSPS, FY2016-2018).

\section{REFERENCES}

1. Chin, T. S., and Chen, J. C., 1987. Acute toxicity of ammonia to larvae of the tiger prawn, Penaeus monodon. Aquaculture, 66(3-4), 247-253.

2. Muir, P. R., Sutton, D. C., and Owens, L., 1991. Nitrate toxicity to Penaeus monodon protozoea. Marine Biology, 108(1), 67-71.

3. Boyd, C. E., 1998. Water quality for pond aquaculture. Alabama Agriculture Experimental Station, Auburn University, Alabama. 37 pp.

4. Gross, A., Abutbul, S., and Zilberg, D., 2004. Acute and Chronic Effects of Nitrite on white shrimp, Litopenaeus vannamei, cultured in low-salinity brackish water. Journal of the World Aquaculture Society, 35(3), 315-321.

5. Chopin, T., Buschmann, A. H., Halling, C., Troell, M., Kautsky, N., Neori, A., Kraemer, G. P., Zertuche-González, J. A., Yarish, C., and Neefus, C., 2001. Integrating seaweeds into marine aquaculture systems: a key toward sustainability. Journal of Phycology, 37(6), 975-986.

6. Burford, M. A., Costanzo, S. D., Dennison, W. C., Jackson, C. J., Jones, A. B., McKinnon, A. D., Preston, N. P., and Trott, L. A., 2003. A synthesis of dominant ecological processes in intensive shrimp ponds and adjacent coastal environments in NE Australia. Marine Pollution Bulletin, 46(11), 1456-1469.

7. Worm, B., Sandow, M., Oschlies, A., Lotze,
H. K., and Myers, R. A., 2005. Global patterns of predator diversity in the open oceans. Science, 309(5739), 1365-1369.

8. Anh, P. T., Kroeze, C., Bush, S. R., and Mol, A. P., 2010. Water pollution by intensive brackish shrimp farming in southeast Vietnam: Causes and options for control. Agricultural Water Management, 97(6), 872-882.

9. Parker, A. E., Dugdale, R. C., and Wilkerson, F. P., 2012. Elevated ammonium concentrations from wastewater discharge depress primary productivity in the Sacramento river and the Northern San Francisco estuary. Marine Pollution Bulletin, 64(3), 574-586.

10. Isobe, K., and Ohte, N., 2014. Ecological perspectives on microbes involved in $\mathrm{N}$ cycling. Microbes and Environments, 29(1), 4-16.

11. Prabhu, N. M., Nazar, A. R., Rajagopal, S., and Khan, S. A., 1999. Use of probiotics in water quality management during shrimp culture. Journal of Aquaculture in the Tropics, 14(3), 227-233.

12. Shariff, M., Yusoff, F. M., Devaraja, T. N., and Rao, P. S., 2001. The effectiveness of a commercial microbial product in poorly prepared tiger shrimp, Penaeus monodon (Fabricius), ponds. Aquaculture Research, 32(3), 181-187.

13. Sambasivam, S., Chandran, R., and Khan, S. A., 2003. Role of probiotics on the environment of shrimp pond. Journal of Environmental Biology, 24(1), 103-106.

14. Rombaut, G., Grommen, R., Zizhong, Q., Vanhoof, V., Suantika, G., Dhert, P., Sorgeloos, P., and Verstraete, W., 2003. Improved performance of an intensive rotifer culture system by using a nitrifying inoculum (ABIL). Aquaculture Research, 34(2), 165-174.

15. Janeo, R. L., Corre, V. L., and Sakata, T., 2009. Water quality and phytoplankton stability in response to application frequency of bioaugmentation agent in shrimp ponds. Aquacultural Engineering, 40(3), 120-125. 
16. Barik, P., Vardia, H. K., and Gupta, S. B., 2011. Bioremediation of ammonia and nitrite in polluted water. International Journal of Fisheries and Aquaculture, 3(7), 136-142.

17. Stephenson, D., and Stephenson, T., 1992. Bioaugmentation for enhancing biological wastewater treatment. Biotechnology Advances, 10(4), 549-559.

18. Gatesoupe, F. J., 1999. The use of probiotics in aquaculture. Aquaculture, 180(1), 147-165.

19. Diab, S., and Shilo, M., 1988. Effect of adhesion to particles on the survival and activity of Nitrosomonas sp. and Nitrobacter sp. Archives of Microbiology, 150(4), 387-393.

20. Shan, H., and Obbard, J., 2001. Ammonia removal from prawn aquaculture water using immobilized nitrifying bacteria. Applied Microbiology and Biotechnology, 57(5), 791-798.

21. Manju, N. J., Deepesh, V., Achuthan, C., Rosamma, P., and Singh, I. B., 2009. Immobilization of nitrifying bacterial consortia on wood particles for bioaugmenting nitrification in shrimp culture systems. Aquaculture, 294(1), 6575.

22. Chen, S., Ling, J., and Blancheton, J. P., 2006. Nitrification kinetics of biofilm as affected by water quality factors. Aquacultural Engineering, 34(3), 179-197.

23. Neori, A., Chopin, T., Troell, M., Buschmann, A. H., Kraemer, G. P., Halling, C., Shpigel, M., and Yarish, C., 2004. Integrated aquaculture: rationale, evolution and state of the art emphasizing seaweed biofiltration in modern mariculture. Aquaculture, 231(1), 361-391.

24. Marinho-Soriano, E., Azevedo, C. A. A., Trigueiro, T. G., Pereira, D. C., Carneiro, M. A. A., and Camara, M. R., 2011. Bioremediation of aquaculture wastewater using macroalgae and Artemia. International biodeterioration and Biodegradation, 65(1), 253-257.
25. Raja, S., Dinesh, K. P. B., Kesavan, K., Kodungallur, T., and Thrissur, K., 2014. Bioremediation by using of microbes and algae with special reference to coastline environment. Int. J. Biosci. Nanosci, 1(6), 130-140.

26. Watson, S. W., Bock, E., Harms, H., Koops, H., and Hooper, A. B., 1989. Nitrifying bacteria, in Bergey's Manual of Systematic Bacteriology (eds Stanley, J. T., Bryant, M. P., Pfennig, N., and Holt, J. G.), Williams \& Wilkins, Baltimore, pp. 1808-1834.

27. Solorzano, L., 1969. Determination of ammonia in natural waters by the phenolhypochlorite method. This research was fully supported by US Atomic Energy Commission Contract No. ATS (11-1) GEN 10, PA 20. Limnology and oceanography, 14(5), 799-801.

28. Strickland, J. D., and Parsons, T. R., 1972. A practical handbook of seawater analysis. Fisheries Research Board of Canada, Ottawa.

29. Grommen, R., Van Hauteghem, I., Van Wambeke, M., and Verstraete, W., 2002. An improved nitrifying enrichment to remove ammonium and nitrite from freshwater aquaria systems. Aquaculture, 211(1), 115-124.

30. Van Rijn, J., Tal, Y., and Schreier, H. J., 2006. Denitrification in recirculating systems: theory and applications. Aquacultural Engineering, 34(3), 364-376.

31. Tal, Y., Schreier, H. J., Sowers, K. R., Stubblefield, J. D., Place, A. R., and Zohar, Y., 2009. Environmentally sustainable landbased marine aquaculture. Aquaculture, 286(1), 28-35.

32. Müller-Belecke, A., Zienert, S., Thürmer, C., Kaufhold, S., and Spranger, U., 2013. The "self cleaning inherent gas denitrification-reactor" for nitrate elimination in RAS for pike perch (Sander lucioperca) production. Aquacultural Engineering, 57, 18-23.

33. McGowan, C. J., 2007. Nitrification Potential and Nitrate Reduction to Ammonium in a Nitrogen-Polluted Estuary 
Doctoral dissertation, Brown University, (date). 29 pp.

34. Ando, Y., Nakagawa, T., Takahashi, R., Yoshihara, K., and Tokuyama, T., 2009. Seasonal changes in abundance of ammonia-oxidizing archaea and ammoniaoxidizing bacteria and their nitrification in sand of an eelgrass zone. Microbes and Environments, 24(1), 21-27.
35. Chen, G. H., Ozaki, H., and Terashima, Y., 1989. Modelling of the simultaneous removal of organic substances and nitrogen in a biofilm. Water Science and Technology, 21(8-9), 791-804.

36. Gujer, W., and Boller, M., 1986. Design of a nitrifying tertiary trickling filter based on theoretical concepts. Water Research, 20(11), 1353-1362. 